\title{
Return to Work After Cancer Diagnosed in 2002, 2005 and 2008
}

\author{
C. A. M. Roelen • P. C. Koopmans • \\ J. W. Groothoff • J. J. L. van der Klink • \\ U. Bültmann
}

Published online: 28 July 2011

(c) The Author(s) 2011. This article is published with open access at Springerlink.com

\begin{abstract}
Introduction Improvements in diagnosis and treatment of cancer have increased cancer survival. This study investigated the trends in return to work (RTW) after cancer. Methods All employees absent from work due to cancer diagnosed in 2002 ( $\mathrm{N}=1209), 2005(\mathrm{~N}=1522)$, and $2008(\mathrm{~N}=1556)$ were selected from an occupational health service register. Partial RTW was defined as resuming work with $50 \%$ of earnings and full RTW as resuming work with $100 \%$ of earnings. The percentages of partial and full RTW were determined 2 years after reporting sick and compared with percentages of partial and full RTW after cardiovascular disorders. The time to partial and full RTW after cancer in 2005 and 2008 was compared with the time to RTW in 2002. Results Partial RTW decreased from $85 \% 2$ years after cancer diagnosis in 2002 to $80 \%$ in 2005 and $69 \%$ in 2008. Full RTW decreased from $80 \% 2$ years after cancer diagnosis in 2002 to $74 \%$ in 2005 and $60 \%$ in 2008 . RTW after cardiovascular disorders showed similar changes. The time to partial RTW in 2008 was longer than in 2002 after gastrointestinal cancer and lung cancer. The time to full RTW in 2008 was longer than in 2002 after breast cancer, gastrointestinal
\end{abstract}

C. A. M. Roelen - J. W. Groothoff - J. J. L. van der Klink ·

U. Bültmann

Department of Health Sciences, University Medical Center

Groningen, University of Groningen, PO Box 196,

9700 AD Groningen, The Netherlands

C. A. M. Roelen ( $\square)$

365ArboNed Corporate Accounts, PO Box 158,

8000 AD Zwolle, The Netherlands

e-mail: corne.roelen@arboned.nl

P. C. Koopmans

365ArboNed Groningen, PO Box 141, 9700 AC Groningen,

The Netherlands cancer and lung cancer. Conclusions In the past decade, the percentages of employees who resumed work after cancer have decreased in The Netherlands, while the time to RTW increased. Possible explanations include changes in disability policy, economic decline, and resulting decreases in work latitude and workplace accommodations.

Keywords Cancer - Neoplasms - Epidemiology ·

Occupational health $\cdot$ Sick-leave $\cdot$ Vocational rehabilitation

\section{Introduction}

Cancer is a priority health issue in the European Union, which was formalized in the European Partnership for Action against Cancer launched in September 2009. This partnership supports countries in their efforts to deal with cancer by providing a framework for sharing information and expertise in cancer prevention and treatment among a wide range of stakeholders [1]. The annual incidence of cancer has been estimated at 338 per 100,000 persons in eastern European countries and 447 per 100,000 persons in western European countries [2]. Cancer survival is highest in the Scandinavian countries and lowest in the Czech Republic, Poland, and Slovenia [3].

The age-adjusted 5-year survival for all cancers has improved in Europe from $44 \%$ in 1989 to $50 \%$ in 1998. The increase was almost linear up to 1994-1996 and then slowed [4]. Major survival increases were found in patients with prostate cancer, colorectal cancer, and breast cancer, whereas survival increases were small for cancers of the lung and cervix. The 5-year survival of women increased from 52\% in 1989 to 59\% in 1998 and the 5-year survival of men from 34 to $39 \%$ with a significant trend heterogeneity between the sexes [4-6]. Survival trends were also 
heterogeneous with age in that younger patients had a greater increase in survival than older patients of both sexes.

The increasing cancer survival means that more and more individuals resume their everyday life, which also includes remaining in or returning to work. Return to work is frequently viewed as an indicator of recovery from cancer [7]. Cancer survivors may try to re-establish their former structure of everyday life and get back to work after treatment, because they see this as a normal and healthy existence [8]. In that case, it is likely that return to work rates after cancer will have increased parallel to the improved cancer survival. This assumption is supported by studies of the employment status of cancer survivors 3-20 years after diagnosis. Studies performed between 1986 and 1999 reported that 62\% (range 30-93\%) of cancer survivors was employed 3-20 years after diagnosis, and studies performed between 2000 and 2006 found $71 \%$ (range $41-84 \%$ ) of cancer survivors to be employed [9-17]. However, comparison of employment statistics is impeded by differences in social security systems across countries and by both how and when (un)employment was assessed. Moreover, the employment status 3-20 years after cancer diagnosis reflects sustaining work rather than resuming work after cancer.

The present study investigated return to work (RTW) within 2 years of cancer diagnosis in 2002, 2005, and 2008 using sickness absence data recorded in an occupational health service register. RTW after cancer was investigated in two ways. First, the percentage of employees who resumed work was measured 2 years after cancer diagnosis. To distinguish between cancer-specific trends and national trends, the percentage of employees with RTW after cancer was compared with the percentage of employees with RTW after cardiovascular disorders in 2002, 2005, and 2008. Second, the time to RTW after cancer in 2005 and in 2008 was compared with the time to RTW after cancer in 2002.

\section{Methods}

\section{Study Setting}

In The Netherlands, employers report the dates on which employees call in sick and the dates they resume work partially or fully to an occupational health service for recording purposes and as a request to start medical guidance of the sick-listed employee. Sick-listed employees visit the occupational physician (OP) usually in the third week of absence from work for a medical certification of sickness absence. The OP records the diagnosis of the sickness certificate in the sickness absence register using the codes of the 10th version of the International Classification of Diseases (ICD-10), and evaluates recovery and return to work activities every 4 to 6 weeks.

\section{Ethical Considerations}

Approval from a medical ethics board was not necessary for this study, because the Act on Scientific Medical Research does not apply to research on anonymized records. Employees gave informed consent to the use their sickness absence data for scientific analysis.

\section{Study Population}

Between 2002 and 2010, the sickness absence register of 365ArboNed contained the sickness absence data and medical diagnoses of more than one million employees. The employees worked in 33,000 companies of different economic sectors representative of the Dutch workforce, except for the primary sector (i.e., agriculture, forestry, fishery, and mining) which was under-represented in the register.

From the 365ArboNed Occupational Health Service register, the sickness absence episodes certified by the OP as being due to breast cancer (ICD-10 C50), genital cancer (ICD-10 C51-C63), gastrointestinal cancer (ICD-10 C15C26), lung cancer (ICD-10 C30-C39), skin cancer (ICD-10 C43-C44), or blood malignancies (ICD-10 C81-C96) in 2002, 2005, and 2008 were selected.

For comparison, sickness absence episodes certified as being due to cardiovascular disorders (ICD-10 I21, i.e. acute myocardial infarction and ICD-10 I64, i.e. stroke not specified as hemorrhage or infarction) in 2002, 2005, and 2008 were selected from the register. Cardiovascular disorders were chosen as a reference, because, like most cancers, cardiovascular disorders are more common in older employees and the median duration of sickness absence due to cardiovascular disorders (295 days) was comparable with the mediation duration of sickness absence due to cancer (309 days).

In this study, partial RTW was defined as resuming work with $50 \%$ of the earnings before sickness absence for at least 28 consecutive days. Full RTW was defined as resuming work with $100 \%$ of the earnings before sickness absence for at least 28 consecutive days. The follow-up period for monitoring RTW was restricted to 2 years, because the registration of sickness absence ended at the moment employees were awarded a disability pension after 2 years of sickness absence.

Statistical Analysis

The percentages of employees with partial and full RTW 2 years after cancer diagnosis in 2002, 2005, and 2008 were 
compared by $\chi^{2}$ analyses. A $1 \%$ significance level was chosen because of the number of $\chi^{2}$ tests performed for each type of cancer. Interaction between diagnosis and year was examined to reveal whether changes in the percentages of RTW after cancer differed from cardiovascular disorders.

The time to RTW was determined by Cox proportional hazards regression analysis for each type of cancer. The Cox regression estimated hazard ratios (HR) and 99\% confidence intervals (CI) of the time to partial and full RTW in 2005 and 2008. A HR $<1$ reflects a longer time to RTW and a HR $>1$ a shorter time to RTW compared to 2002. The hazard ratios were adjusted for age. The data of patients who resigned, retired, or died within 2 years of diagnosis were censored. All analyses were performed in SPSS for Windows version 18.

\section{Results}

In 2002, 1209 employees (1.21\%o) reported sick because they were diagnosed with cancer at a mean age of 47.5 (standard deviation $(\mathrm{SD})=9.2$ ) years. In 2005, 1522 employees $(1.52 \%$ ) with a mean age of $47.8(\mathrm{SD}=10.0)$ years reported sick due to cancer and in 2008, 1556 employees $(1.56 \%)$ with a mean age of $49.1(\mathrm{SD}=9.8)$ years. In the period from 2002 to 2008, the number of episodes of sickness absence due to cancer increased, especially among employees aged $\geq 50$ years (Table 1 ).

\section{Percentage of Employees with RTW}

Overall, $85 \%$ of employees had partially resumed work 2 years after cancer diagnosed in $2002,80 \%$ after cancer in 2005 and 69\% after cancer in 2008 (Table 2). There was an increase in the percentage of employees with partial RTW after skin cancer from $87 \%$ in 2002 to $92 \%$ in 2008 , but this change was not significant $(p=0.53)$. The percentage of employees with partial RTW decreased significantly for most cancers, except blood malignancies, and in all age categories. In comparison, the percentage of employees with partial RTW after cardiovascular disorders decreased from $89 \%$ in 2002 to $81 \%$ in 2008 . There was no significant interaction between diagnosis and year $(p=0.51)$ indicating that the decrease in partial RTW over time did not differ between the diagnoses.

The percentages of employees with full RTW decreased from $80 \% 2$ years after cancer diagnosed in 2002 to $74 \%$ after cancer in 2005 and $60 \%$ after cancer in 2008 (Table 2). The percentage of full RTW also decreased in employees with cardiovascular disorders from $87 \%$ in 2002 to $75 \%$ in 2008 . The decline in full RTW over time did not differ significantly between the diagnoses $(p=0.30)$. The percentages of employees with full RTW after cancer
Table 1 Numbers of employees absent from work due to cancer in 2002, 2005, and 2008

\begin{tabular}{|c|c|c|c|}
\hline $\begin{array}{l}\text { Total number of } \\
\text { employees in } \\
\text { the register }\end{array}$ & $\begin{array}{l}2002 \\
\mathrm{~N}=1,011,555\end{array}$ & $\begin{array}{l}2005 \\
\mathrm{~N}=1,010,686\end{array}$ & $\begin{array}{l}2008 \\
\mathrm{~N}=1,012,345\end{array}$ \\
\hline \multicolumn{4}{|l|}{ Breast cancer } \\
\hline Women & 401 & 516 & 514 \\
\hline Men & - & - & - \\
\hline \multicolumn{4}{|l|}{ Genital cancer } \\
\hline Women & 191 & 305 & 234 \\
\hline Men & 95 & 130 & 164 \\
\hline \multicolumn{4}{|c|}{ Gastrointestinal cancer } \\
\hline Women & 62 & 71 & 85 \\
\hline Men & 162 & 162 & 212 \\
\hline \multicolumn{4}{|l|}{ Lung cancer } \\
\hline Women & 44 & 56 & 67 \\
\hline Men & 88 & 89 & 99 \\
\hline \multicolumn{4}{|l|}{ Skin cancer } \\
\hline Women & 28 & 42 & 31 \\
\hline Men & 51 & 55 & 66 \\
\hline \multicolumn{4}{|c|}{ Blood malignancies } \\
\hline Women & 29 & 32 & 26 \\
\hline Men & 58 & 64 & 58 \\
\hline \multicolumn{4}{|l|}{ All cancers } \\
\hline$<40$ years & $260(22 \%)$ & $344(23 \%)$ & $274(18 \%)$ \\
\hline $40-49$ years & $393(33 \%)$ & $447(29 \%)$ & $420(27 \%)$ \\
\hline$\geq 50$ years & $549(45 \%)$ & $728(48 \%)$ & $856(55 \%)$ \\
\hline Missing & 2 & 3 & 6 \\
\hline $\begin{array}{l}\text { Total cancer } \\
\text { cases }\end{array}$ & $1209(100 \%)$ & $1522(100 \%)$ & $1556(100 \%)$ \\
\hline \multicolumn{4}{|l|}{ Reference $^{\mathrm{a}}$} \\
\hline$<40$ years & $82(10 \%)$ & $112(11 \%)$ & $89(9 \%)$ \\
\hline 40-49 years & $302(36 \%)$ & $320(32 \%)$ & $311(32 \%)$ \\
\hline$\geq 50$ years & $457(54 \%)$ & $562(57 \%)$ & $576(59 \%)$ \\
\hline Missing & - & 1 & 1 \\
\hline $\begin{array}{l}\text { Total } \\
\text { reference } \\
\text { group }\end{array}$ & $841(100 \%)$ & $995(100 \%)$ & $977(100 \%)$ \\
\hline
\end{tabular}

$\overline{{ }^{a}}$ The reference group consisted of employees sick-listed with cardiovascular disorders

decreased in all age categories, whereas the percentage of full RTW did not change significantly after cardiovascular disorders in employees $<40$ years of age.

\section{Time to Partial and Full RTW}

While the percentage of RTW indicates how many employees had resumed work 2 years after cancer diagnosis, the time to RTW is a measure that reflects the duration until RTW. The mean duration until partial RTW 
Table 2 Percentage of employees resuming work within 2 years of diagnosis

\begin{tabular}{|c|c|c|c|c|c|c|c|c|}
\hline & \multicolumn{2}{|l|}{2002} & \multicolumn{2}{|l|}{2005} & \multicolumn{2}{|l|}{2008} & \multicolumn{2}{|l|}{$\chi^{2} p$-value } \\
\hline & Partial $^{\mathrm{a}}(\%)$ & Full $^{\mathrm{b}}(\%)$ & $\operatorname{Partial}^{\mathrm{a}}(\%)$ & Full $^{\mathrm{b}}(\%)$ & Partial $^{\mathrm{a}}(\%)$ & Full $^{\mathrm{b}}(\%)$ & Partial $^{\mathrm{a}}(\%)$ & Full $^{\mathrm{b}}(\%)$ \\
\hline Breast cancer & 88 & 85 & 82 & 75 & 71 & 59 & $<0.01$ & $<0.01$ \\
\hline Genital cancer & 94 & 91 & 91 & 88 & 85 & 79 & 0.01 & $<0.01$ \\
\hline Gastrointestinal cancer & 78 & 72 & 69 & 63 & 53 & 44 & $<0.01$ & $<0.01$ \\
\hline Lung cancer & 65 & 61 & 52 & 47 & 41 & 33 & $<0.01$ & $<0.01$ \\
\hline Skin cancer & 87 & 80 & 92 & 88 & 92 & 86 & 0.53 & 0.34 \\
\hline Blood malignancies & 83 & 76 & 72 & 68 & 68 & 54 & 0.07 & $<0.01$ \\
\hline \multicolumn{9}{|l|}{ All cancers } \\
\hline Total & 85 & 80 & 80 & 74 & 69 & 60 & $<0.01$ & $<0.01$ \\
\hline$<40$ years & 91 & 87 & 81 & 77 & 76 & 69 & $<0.01$ & $<0.01$ \\
\hline $40-49$ years & 86 & 81 & 83 & 77 & 72 & 60 & $<0.01$ & $<0.01$ \\
\hline$\geq 50$ years & 81 & 77 & 77 & 71 & 65 & 57 & $<0.01$ & $<0.01$ \\
\hline \multicolumn{9}{|l|}{ Reference $^{\mathrm{c}}$} \\
\hline Total & 89 & 87 & 87 & 83 & 81 & 75 & $<0.01$ & $<0.01$ \\
\hline$<40$ years & 89 & 87 & 85 & 78 & 78 & 78 & 0.12 & 0.23 \\
\hline $40-49$ years & 91 & 89 & 90 & 86 & 80 & 76 & $<0.01$ & $<0.01$ \\
\hline$\geq 50$ years & 89 & 86 & 86 & 82 & 82 & 74 & $<0.01$ & $<0.01$ \\
\hline
\end{tabular}

${ }^{a}$ Return to work with $50 \%$ or more of the earnings before sickness absence

b Return to work with equal earnings as before sickness absence

c The reference group consisted of employees sick-listed with cardiovascular disorders

Table 3 Age-adjusted time to return to work after cancer

\begin{tabular}{|c|c|c|c|c|c|c|}
\hline & \multicolumn{3}{|c|}{ Partial RTW ${ }^{\mathrm{a}}$} & \multicolumn{3}{|c|}{ Full RTW ${ }^{\mathrm{b}}$} \\
\hline & 2002 & 2005 & 2008 & 2002 & 2005 & 2008 \\
\hline Breast cancer & 1.00 & $0.91(0.76-1.10)$ & $0.87(0.72-1.06)$ & 1.00 & $0.82(0.67-0.99) * *$ & $0.70(0.57-0.86)^{* *}$ \\
\hline Genital cancer & 1.00 & $1.07(0.87-1.32)$ & $1.06(0.86-1.31)$ & 1.00 & $1.03(0.84-1.28)$ & $1.01(0.85-1.25)$ \\
\hline Gastrointestinal cancer & 1.00 & $0.82(0.62-1.09)$ & $0.66(0.50-0.88)^{* *}$ & 1.00 & $0.79(0.59-1.07)$ & $0.57(0.42-0.77)^{* *}$ \\
\hline Lung cancer & 1.00 & $0.75(0.50-1.13)$ & $0.56(0.37-0.85)^{* *}$ & 1.00 & $0.67(0.44-1.04)$ & $0.46(0.29-0.72)^{* *}$ \\
\hline Skin cancer & 1.00 & $1.25(0.83-1.89)$ & $1.29(0.85-1.96)$ & 1.00 & $1.37(0.89-2.11)$ & $1.25(0.81-1.93)$ \\
\hline Blood malignancies & 1.00 & $0.73(0.47-1.14)$ & $0.75(0.47-1.18)$ & 1.00 & $0.79(0.50-1.26)$ & $0.64(0.39-1.05)$ \\
\hline Total & 1.00 & $0.95(0.85-1.06)$ & $087(0.78-0.98)^{* *}$ & 1.00 & $0.91(0.81-1.02)$ & $0.76(0.68-0.86)^{* *}$ \\
\hline
\end{tabular}

The table shows age-adjusted hazard ratios (99\% confidence intervals). A hazard ratio $<1$ reflects a longer time to RTW compared to 2002 , and a hazard ratio $>1$ reflects a shorter time compared to 2002; ** $p<0.01$

a Return to work with $50 \%$ or more of the earnings before sickness absence

b Return to work with equal earnings as before sickness absence

was 264 (99\% confidence interval 249-279) days after cancer diagnosis in 2002 and 297 (279-315) days in 2008. The time to partial RTW after cancer in 2008 was longer than the time to partial RTW after cancer in 2002, particularly after gastrointestinal cancer and lung cancer (Table 3). The mean duration until full RTW was 318 (302-334) days after cancer diagnosis in 2002 and 343 (325-361) days in 2008. Again, the time to full RTW was longer after cancer diagnosed in 2008 as compared to 2002, especially for breast cancer, gastrointestinal cancer, and lung cancer.

\section{Discussion}

This study investigated the trend in RTW within 2 years of cancer diagnosis stratified by cancer site. The number of employees who resumed work after cancer was lower in 2008 compared with 2002 as was reflected in a lower percentage of RTW at 2 years after cancer diagnosis. Similar trends were observed for RTW after cardiovascular disorders. The age-adjusted hazard ratios indicated a longer duration until both partial and full RTW after cancer in 2008 as compared with 2002. 
Percentage of Employees with RTW

The decline in the percentage of employees who returned to work may be due to changes in the sickness absence compensation policies. Before 2004, employers or employers' insurers compensated sickness absence for a maximum period of 1 year, after which sick-listed employees were assessed for a disability pension. If a disability pension was awarded, employees were discharged from their company and removed from the sickness absence register. Thus, the employees who had not resumed work within 1 year of reporting sick in 2002 were removed from the register. Since 2004, the employer or employer's insurer have to compensate and register sickness absence for a period of 2 years. Hence, the differences between the RTW percentages in 2002 and 2005 are likely to be due to differences in the period during which sickness absence was compensated and registered.

The sickness absence compensation policies did not change between 2005 and 2008. Thus, the further decrease in the percentages of partial and full RTW in 2008 compared with 2005 can not be attributed to changes in sickness absence policies or registration. Furthermore, a cancer-specific explanation is not likely as a similar decline in RTW percentages was also found in employees sick-listed with cardiovascular disorders. The economic recession resulting from the financial crisis in 2008 may explain why the RTW percentages were lower in 2008 compared with 2005 as it has been reported that sickness absence is related to the economic situation [18, 19]. However, Dutch sickness absence statistics show that $4.4 \%$ of the working days were lost due to sickness in 2005 compared with $4.3 \%$ of the working days in both 2008 and 2009 [20]. Although there was no increase in sickness absence in the working population, unemployment has increased from 174,000 persons in 2008 to 220,000 persons in 2009 and an estimated 267,000 persons in 2010 [20]. Therefore, another explanation for the lower percentages of RTW within 2 years of reporting sick in 2008 might be that employees were more often discharged after long-term sickness absence in 2008. A final explanation for the lower percentage of RTW may be that employees' priorities in life have changed after having experienced a life-threatening disease [10, 11]. Earlier studies have shown that employees put less value on resuming work and may prefer having more leisure time to spend with family and friends or enjoy hobbies $[7,8,21]$. However, the sickness absence register provided no information on how employees valued returning to work after cancer.
Time to Partial and Full RTW

The results of this study not only show lower percentages of employees with partial or full RTW, but also a longer duration until RTW after cancer in 2008 as compared with 2002, particularly for breast cancer, gastrointestinal cancer and lung cancer. The longer time to RTW may be due to changes in company sickness absence policies. In The Netherlands, both employer and sick-listed employee are responsible for occupational rehabilitation. From the start of sickness absence, employers have to stay in contact with the employee and, if possible, have to arrange modified work duties or adjust work hours so that the sick-listed employee remains in connection with the workplace. Perhaps, the financial crisis in 2008 made it less attractive for employers to invest in work adjustments or in occupational rehabilitation programs, which might have led to exclusion of longterm sick-listed employees from the workplace. Furthermore, it was recognized that a supportive work environment facilitated RTW of cancer survivors [9, 15, 22, 23]. Failure to create a 'welcome back' work environment due to financial economic problems of companies might also explain the longer time to RTW in 2008 compared with 2005.

Apart from policies and procedures, work-related factors determine the work outcomes after cancer. The work environment was already mentioned, but physical, cognitive, and emotional work demands are also important [22]. From an employee's perspective, work is changing and becoming more and more mentally demanding. Although the level of job control in The Netherlands is relatively high, annual surveys of working conditions showed a steady increase in psychosocial job demands [24]. For example, 24\% of employees experienced a high work pace and $33 \%$ a high work pressure in 2005 compared with 34 and 41\%, respectively, in 2008 . These increases in work pace and pressure may explain the longer time to RTW in 2008 compared with 2005.

Alternatively, medical factors also explain the finding that the time to RTW was longer after cancer diagnosis in 2008 compared with 2002. Breast cancer is one of the most common cancers in individuals of working age. In The Netherlands, the indication for chemotherapy was broadened for young women with breast cancer in 2004 [25]. It has been recognized that patients who received chemotherapy experienced more problems in resuming work and returned to work later than those who were not treated with chemotherapy [26-32].

Strengths and Limitations of the Study

A strength of the study was that it covered a large population of more than one million employees representative 
of the Dutch workforce. The registration of sickness absence diagnoses did not change during the period of study and there were no substantial changes in covered industries over time. Furthermore, the outcome of partial RTW next to full RTW provided good insight into resuming work after cancer, even if employees decided to work in lower earnings or lower-wage jobs for physical or psychological reasons.

Although sickness absence register studies can be performed rather inexpensively in large numbers of employees, the most important limitation is that the number of variables available from the sickness absence register is limited. The sickness absence register contained social security numbers linking information on name, address, age, gender, and company to the sickness absence dates and diagnoses. Information on work conditions was available, but was not up to date though these factors are known to play an important role in RTW after cancer [9-16, 22]. Additional medical information was not available from the sickness absence register, while RTW after cancer depends on the cancer stage, site, treatment, and comorbidity $[9,22$, 23]. Another limitation was that information on actual job demands, work accommodations to facilitate RTW after cancer, and the willingness of employers to accommodate an early RTW was lacking.

In conclusion, the RTW percentage after cancer has decreased in The Netherlands, but a similar decline was observed for RTW after cardiovascular disorders. Furthermore, the time to RTW was longer after cancer diagnosis in 2008 as compared with 2002. RTW should be monitored in different countries to reveal the trends in RTW after cancer in other countries. Continued attention for RTW after cancer is required, because the results of this study showed an increasing incidence of cancer in the working population, particularly among employees aged $\geq 50$ years. Hence, sickness absence and RTW of cancer survivors is likely to be an increasing problem to be addressed in the ageing working population.

Open Access This article is distributed under the terms of the Creative Commons Attribution Noncommercial License which permits any noncommercial use, distribution, and reproduction in any medium, provided the original author(s) and source are credited.

\section{References}

1. COM 291/4. Fighting cancer: a European partnership is born. Brussels: Commission of the European Communities, 2009.

2. International Agency for Research on Cancer. The GLOBOCAN 2002 software and database version 2.0. Available from: http://www-dep.iarc.fr/globocan/database.html.

3. Sant M, Allemani C, Santaguilani M, Knijn A, Marchesi F, Capocaccia R, The EUROCARE-4 Working Group. Survival of cancer patients diagnosed in 1995-1999. Results and commentary. Eur J Cancer. 2009;45:931-91.
4. Verdecchia A, Guzzinati S, Francisci S, et al. Survival trends in European cancer patients diagnosed from 1988 to 1999. Eur J Cancer. 2009;45:1042-66.

5. Verdecchia A, Francisci S, Brenner H, EUROCARE-4 Working Group, et al. Recent cancer survival in Europe: a 2000-2 period analysis of EUROCARE-4 data. Lancet Oncol. 2007;8:784-96.

6. Francisci S, Capocaccia R, Grande E, EUROCARE-4 Working Group, et al. The cure of cancer: a European perspective. Eur J Cancer. 2009;45:1067-79.

7. Kennedy F, Haslam C, Munir F, Pryce J. Returning to work following cancer: a qualitative exploratory study into the experience of returning to work following cancer. Eur J Cancer Care. 2007;16:17-25.

8. Rasmussen DM, Elverdam B. The meaning of work and working life after cancer: an interview study. Psychooncology. 2008;17: 1232-8.

9. Taskila T. Cancer survivors and work. Work-related problems and factors associated with their employment, work ability and social support from the work community. Helsinki: Finnish Institute of Occupational Health; 2007.

10. Bradley CJ, Bednarek HL. Employment patterns of long-term cancer survivors. Pyschooncology. 2002;11:188-98.

11. Bednarek HL, Bradley CJ. Work and retirement after cancer diagnosis. Res Nurs Health. 2005;28:126-35.

12. Taskila T, Lindbohm ML. Factors affecting cancer survivors' employment and work ability. Acta Oncol. 2007;46:446-51.

13. Bradley CJ, Bednarek HL, Neumark D. Breast cancer survival, work, and earnings. J Health Econ. 2002;21:757-79.

14. Short PF, Vasey JJ, Tucelli K. Employment patterns in a large cohort of adult cancer survivors. Cancer. 2005;103:1292-301.

15. Taskila T, Martikainen R, Hietanen P, Lindbohm ML. Comparative study of work ability between cancer survivors and their referents. Eur J Cancer. 2007;43:914-20.

16. Lavigne JE, Griggs JJ, Tu XM, Lerner DJ. Hot flashes, fatigue, treatment exposures and work ability between cancer survivors and their referents. Eur J Cancer. 2007;43:914-20.

17. Hansen JA, Feuerstein M, Calvio LC, Olsen CH. Breast cancer survivors at work. J Occup Environ Med. 2008;50: 777-84.

18. Virtanen M, Kivimäki M, Elovaino M, Virtanen P, Vahtera J. Local economy and sickness absence: prospective cohort study. J Epidemiol Community Health. 2005;59:973-8.

19. Hesselius P. Does sickness absence increase the risk of unemployment? J Socio Econ. 2007;36:288-310.

20. Statistics Netherlands. Available from: http://statline.cbs.nl/stat web/.

21. Tiedtke C, de Rijk A, Dierckx de Casterlé B, Christaens M-R, Donceel P. Experiences and concerns about 'returning to work' for women breast cancer survivors: a literature review. Psychooncology. 2010;19:677-82.

22. Feuerstein M, Todd BL, Moskowitz MC, Bruns GL, Stoler MR, Nassif T, Yu X. Work in cancer survivors: a model for practice and research. J Cancer Surviv. 2010;4:415-37.

23. Spelten ER, Sprangers MA, Verbeek JH. Factors reported to influence the return to work of cancer survivors: a literature review. Psychooncology. 2002;11:124-31.

24. Van Hooff M, van den Bossche S, Smulders P. The Netherlands working conditions survey. Available from: http://www.tno.nl/ downloads/TNO-KvL NEA Brochure 2007 Eng.pdf.

25. Sukel MP, van de Poll-Franse LV, Nieuwenhuijzen GA, et al. Substantial increase in the use of adjuvant systemic treatment for early stage breast cancer reflects changes in guidelines in the period 1990-2006 in the southeastern Netherlands. Eur J Cancer. 2008;44:1846-54.

26. Balak F, Roelen CA, Koopmans PC, ten Berge EE, Groothoff JW. Return to work after early-stage breast cancer: a cohort study 
into the effects of treatment and cancer-related symptoms. J Occup Rehabil. 2008;18:267-72.

27. Taskila T, Martikainen R, Hietanen P, Lindbohm ML. Comparative study of work ability between cancer survivors and their referents. Eur J Cancer. 2007;43:914-20.

28. Johnsson A, Fornander T, Olsson M, Nystedt M, Johansson H, Rutqvist LE. Factors associated with return to work after breast cancer treatment. Acta Oncol. 2007;46:90-6.

29. De Boer AG, Verbeek JH, Spelten ER, et al. Work-ability and return-to-work in cancer patients. Br J Cancer. 2008;98:1342-7.
30. Ahn E, Cho J, Sjin W, et al. Impact of breast cancer diagnosis and treatment on work-related life and factors affecting them. Breast Cancer Res Treat. 2009;116:609-16.

31. Johnsson A, Fornander T, Rutqvist LE, Vaez M, Alexanderson K, Olosson M. Predictors of return to work ten months after primary breast cancer surgery. Acta Oncol. 2009;48:93-8.

32. Fantoni SQ, Peugniez C, Duhamel A, Skrzypczak J, Frimat P, Leroyer A. Factors related to return to work by women with breast cancer in Northern France. J Occup Rehabil. 2010;20: $49-58$. 